\title{
Pattern of Cervical Smear Cytology in Calabar, Nigeria,
}

\author{
Odusolu P.O ${ }^{1}$, Omotoso A.J ${ }^{1,2}$, Nnoli $\mathrm{M}^{2}$, Agan T.U ${ }^{1}$, Bassey I.E ${ }^{2}$, \\ Ekanem I. A $^{2}$, Ekanem A.D ${ }^{1}$. \\ ${ }^{I}$ Department of Obstetrics \& Gynaecology, University Calabar Teaching Hospital. \\ ${ }^{2}$ Department of Pathology, University of Calabar Teaching Hospital, Calabar
}

\begin{abstract}
:
Background: Cancer of the cervix is the most common cancer of the female genital tract and accounts for about two hundred and fifty thousand deaths yearly. Most of these occur in the developing countries mainly Africa, because of poverty, lack of awareness, and absence of organised population based screening programmes which has greatly reduced the incidence in the developed world.
\end{abstract}

Objective: The study is aimed at determining the pattern of cervical cytology of smears received in the Department of Pathology, University of Calabar Teaching Hospital, Calabar.

Method: A retrospective study of all cervical smears received and processed at the Department of Pathology, University of Calabar Teaching Hospital, Calabar between January 2001 and December 2010.Those with inadequate data were excluded from the study. Classification was by the Bethesda system and analysis was by simple statistical methods.

Results: During the study period, $98.3 \%$ of the 848 cervical smears received were satisfactory for analysis. Six hundred and ninety eight (83.7\%) were negative smears while (16.3\%) were abnormal, $2.6 \%$ of the abnormal samples were frankly malignant (invasive cancer), while $6.5 \%$ and $5.4 \%$ were high grade squamous intraepithelial lesions (HGSIL) and low grade squamous intraepithelial lesions (LGSIL) respectively.

Conclusion: There is an urgent need for increase awareness for cervical cancer and population screening programmes should be encouraged to reduce the prevalence of cancer of the cervix in our population.

\section{Introduction}

Globally, cancer of the breast is the commonest cancer followed by that of the cervix [1,2], but cancer of the cervix is the commonest in developing countries and the commonest genital tract malignancy. [3, 4, 5,] About half a million new cases are seen worldwide each year with over $80 \%$ of the morbidities and mortalities occurring in developing countries [6]. This is further compounded by the fact that $75 \%$ of patients in developing countries present with advanced stage disease, when only palliative treatment is possible. [7, 8].

Cervical (pap) smear is a relatively simple cost-effective screening test done by scraping the exfoliative epithelium of the squamo - columnar junction of the cervix. This is examined cytologically to detect abnormalities that might lead to cervical cancer [9, 10, and 11]. The prevention of cervical cancer rely on routine population screening for early detection and appropriate management of precursor lesions which if untreated may advance to invasive disease or may regress spontaneously $[12,13]$. Where such programs are effective there has been remarkable reduction in both morbidity and mortality from invasive cancer of the cervix [14]. No form of cancer better documents the remarkable effects of prevention, early diagnosis, and curative therapy on the mortality rate than cancer of the cervix. [2]

In spite of its success and simplicity organized routine screening remains elusive in most developing countries where it is estimated that only about $5 \%$ of women have been screened for the disease with Pap smear. [12]. Most developing countries, including Nigeria, do not have organized cervical cancer screening services, despite the huge burden of cervical cancer and presence of its predisposing factors. Opportunistic screening offers the only hope of preventing cervical cancer in such settings but has severe limitations in its uptake, scope of coverage, follow-up and evaluations of its impact on reduction of clinical cervical cancer. Also, opportunistic screening is characterized by over-screening of those at low risk [15].

A survey of gynaecologists in Nigeria on cervical cancer shows that there is a low level of screening of their patients, despite the availability of screening services in many centres [16]. The low numbers has been attributed to poor preventative health consciousness, the fear of a positive result and concerns about cost [17].

\section{Materials and Methods:}

This is a retrospective study of all (cervical) Pap smears received and processed at the Department of Pathology, University of Calabar Teaching Hospital over a ten year period (January 2001 and December 2010). Specimen adequacy was properly assessed based on presence of endocervical cells and/or metaplastic 
Pattern Of Cervical Smear Cytology In Calabar, Nigeria,

cells as well as adequate number of squamous epithelial cells i.e. more than $10 \%$ of the slide contain squamous cells. The slides were reported according to the 2001 updated version of the Bethesda System for reporting Pap smear results (Apgar et al. 2003). This adopts descriptive diagnoses, including - Benign cellular reactive changes including infections, inflammation, atrophy (Negative) and finally epithelia cell abnormalities which are classified as atypical squamous cells of undetermined significance (ASCUS); Low-grade squamous intraepithelial lesion (LSIL); High-grade squamous intraephielial lesion (HSIL); atypical glandular cells of undetermined significance (AGUS) and invasive carcinoma.

\section{Results:}

The total number of pap smears received was 848 . Fourteen $(1.7 \%)$ were unsatisfactory and therefore not included in the study. Eight hundred and thirty four (834) smears were analyzed. The age range of the women screened was between 17 and 73 years. The largest number of smears was between ages $40-49$ years $(304=36.4 \%)$ and $30-39$ years $(252=30.2 \%)$ while $(162=19.4 \%)$ were 29 years and below and $(118=14 \%)$ were 50 years and above. Only $2.3 \%$ were 60 years and above and $1.4 \%$ were less than 20 years. (Table1).

Majority of the smears $698(83.7 \%)$ were in the category of normal or benign changes hence regarded as negative smears while $136(16.3 \%)$ had abnormal epithelial cell changes and were regarded as positive. These were made of ASCUS 10 (1.2\%), AGUS 5 (0.6\%), LSIL 45 (5.4\%), HSIL was found in 54 (6.5\%) while invasive carcinoma was found in $22(2.6 \%)$ patients. see table 2 .

In Table 3: the highest number of frankly cancerous smears $12(54.6 \%)$ was found in those between 40 and 49 years, followed by $6(27.3 \%)$ in those aged 50 to 59 years while those aged 30 to 39 had $2(9.1 \%)$ and those 60 and above had 2 (9.1\%). The lowest age of those with invasive cancer was 35 years. The HSIL smears also followed the same pattern with the age peak incidence being 40 to $49 y$ rs with 25 (46.3\%), $11(20.4 \%)$ for age range $50-59$ yrs and $7(12.96 \%)$ for those $30-39$ yrs and those above 60 years. Only 4 (7.4\%) people below the age of 30 years had HSIL.

Low grade squamous intraepithelial lesion (LSIL) was seen in 45 cases (5.4\%) with API also between 40-49 years, 7 were seen in those below 30 years while only 3 were seen above 60 years. The mean age of those with LSIL was while the mean age for those with HSIL was Atypical squamous cells of undetermined significance (ASCUS) and atypical glandular cells of undetermined significance (AGUS) were seen in 15 cases (1.8\%). Table 4 shows the distribution of normal and abnormal smears with the percentage of abnormal/normal among the different age groups. For age groups $10-19,20-29$ and $30-39$ the percentages are $8.3 \%, 8.6 \%$ and $8.7 \%$ while for age groups $40-49$ and $50-59$ it is 19.4 and $28.6 \%$. The percentages for age groups $60-69$ and $70-79$ years increased greatly to $71.4 \%$ and $50 \%$ respectively.

Table I. Age Distribution of The Cervical Smears

\begin{tabular}{|l|l|l|}
\hline Age group & Total & Percentage \\
\hline $10-19$ & 12 & 1.4 \\
\hline $20-29$ & 150 & 18.0 \\
\hline $30-39$ & 252 & 30.2 \\
\hline $40-49$ & 304 & 36.4 \\
\hline $50-59$ & 98 & 11.7 \\
\hline $60-69$ & 14 & 1.6 \\
\hline $70-79$ & 6 & 0.7 \\
\hline Total & $\mathbf{8 3 4}$ & $\mathbf{1 0 0}$ \\
\hline
\end{tabular}

Table II Pattern Of Distribution Of The Cervical Smear

\begin{tabular}{|l|c|l|}
\hline LESION & TOTAL & PERCENTAGE \\
\hline NEGATIVE & 698 & 83.7 \\
\hline ASCUS & 10 & 1.2 \\
\hline AGUS & 5 & 0.6 \\
\hline LGSIL & 45 & 5.4 \\
\hline HGSIL & 54 & 6.5 \\
\hline INVASIVE CANCER & 22 & 2.6 \\
\hline TOTAL & $\mathbf{8 3 4}$ & $\mathbf{1 0 0}$ \\
\hline
\end{tabular}

Table III: Showing Abnormal Smears With Age Distribution

\begin{tabular}{|c|c|c|c|c|c|c|c|}
\hline AGE & ASCUS & AGUS & LSIL & HSIL & INVASIVE CA & $\begin{array}{l}\text { TOTA } \\
\text { L }\end{array}$ & $\%$ \\
\hline $10-19$ & - & - & 1 & - & - & 1 & 0.8 \\
\hline $20-29$ & 2 & 1 & 6 & 4 & - & 13 & 9.5 \\
\hline $30-39$ & 3 & 1 & 9 & 7 & 2 & 22 & 16.1 \\
\hline $40-49$ & 5 & - & $\begin{array}{l}1 \\
7\end{array}$ & $\begin{array}{l}2 \\
5\end{array}$ & 12 & 59 & 43.4 \\
\hline $50-59$ & - & 2 & 9 & 1 & 6 & 28 & 20.6 \\
\hline
\end{tabular}


Pattern Of Cervical Smear Cytology In Calabar, Nigeria,

\begin{tabular}{|l|l|l|l|l|l|l|l|}
\hline & & & & 1 & & & \\
\hline $60-69$ & - & 1 & 2 & 5 & 2 & $\mathbf{1 0}$ & $\mathbf{7 . 4}$ \\
\hline $70-79$ & - & - & 1 & 2 & - & $\mathbf{3}$ & $\mathbf{2 . 2}$ \\
\hline Total & $\mathbf{1}$ & $\mathbf{5}$ & $\mathbf{4}$ & $\mathbf{5}$ & $\mathbf{2 2}$ & $\mathbf{1 3 6}$ & $\mathbf{1 0 0}$ \\
& $\mathbf{0}$ & & $\mathbf{5}$ & $\mathbf{4}$ & & & \\
\hline
\end{tabular}

TABLE IV: Distribution Of Normal And Abnormal Smears Among Different Age Groups.

\begin{tabular}{|l|l|l|l|}
\hline Age Group & Normal smears & Abnormal smears & \% of Abnormal/ Normal \\
\hline $10-19$ & 12 & 1 & 8.3 \\
\hline $20-29$ & 150 & 13 & 8.6 \\
\hline $30-39$ & 252 & 22 & 8.7 \\
\hline $40-49$ & 304 & 59 & 19.4 \\
\hline $50-59$ & 98 & 28 & 28.6 \\
\hline $60-69$ & 14 & 10 & 71.4 \\
\hline $70-79$ & 6 & 3 & 50.0 \\
\hline
\end{tabular}

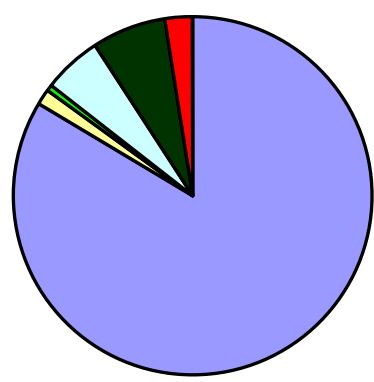

\begin{tabular}{|l|}
\hline NEGATIVE \\
$\square$ ASCUS \\
$\square$ AGUS \\
$\square$ LGSIL \\
$\square$ HGSIL \\
$\square$ INVASIVE CANCER
\end{tabular}

Figure 1 Pie Chart Showing Pattern of Distribution of Different Lesions
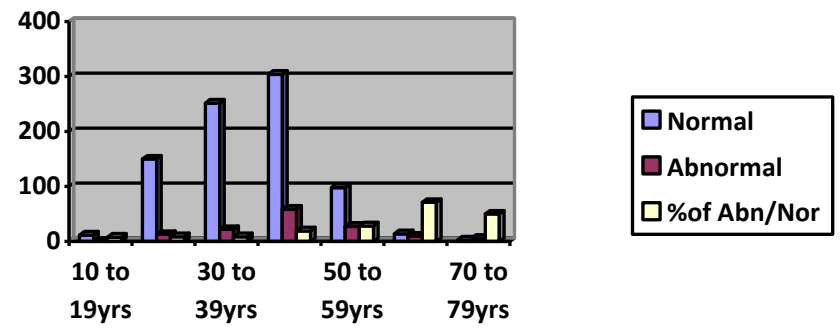

Figure 2: Distribution Of Normal And Abnormal Smears Among Different Age Groups.

\section{Discussion:}

Cervical smears are routinely taken for the purpose of screening for cervical cancer since the clinical disease may be prevented by detection and appropriate management of its precursor.

It is well established in the literature and clinical practice that, the best method of early detection of precancerous lesions of the cervix is by cytological examination of pap smears. Visual inspection of the cervix has been proposed as an alternative to cervical cytology. The unmagnified visual inspection of the cervix after the application of 3-5\% acetic acid which is known as visual inspection of cervix with acetic acid (VIA) seems to be a potentially useful early detection approach. [18]

There is no doubt that regular screening of sexually active women confers an overall public health benefit in reducing the morbidity and mortality from the disease. No form of cancer better documents the remarkable effects of prevention, early diagnosis, and curative therapy on the mortality rate than cancer of the cervix.

Of the eight hundred and thirty four smears analyzed $698(83.7 \%)$ were negative smears, $136(16.3 \%)$ smears had abnormal epithelial cell changes. This agrees with other studies done in northern, mid western and south eastern Nigeria and in Saudi Arabia [9, 19, 17, 21 and 20] while some others had very low abnormal smears [18, 22, and 23].

The age distribution of the women in this study shows that women of all ages will accept Pap smear if they are offered the test. The majority of the women eighty four percent were within the reproductive age group, 
with over sixty percent in the age bracket of 30 to 49 years. Only about 1.4 percent of the women were 19 years and below with 0.8 percent of them having abnormal smears while $2.3 \%$ were 60 years and above with $9.6 \%$ of them having abnormal smears. The increased occurrence of abnormal epithelial smears after 30 years is in agreement with those who advocate that screening should start form 30 years while the presence of abnormal smears in teenagers though small would suggest the need to screen teenagers who are sexually active. [24]

The epithelial abnormalities were as follows, ASCUS 10 (1.2\%), AGUS $5(0.6 \%)$, LSIL $45(5.4 \%)$, HGSIL was found in $54(6.5 \%)$ while invasive carcinoma was found in $22(2.6 \%)$ smears. These are within same limits as some other studies [9,21,].

Women between the ages of 35 and 60 years are at highest risk of developing cervical cancer [9]. In this study, over $95 \%$ of the women with invasive smears fall within this age bracket with the peak age incidence being between 40 and 49 years. There was no invasive cancer in those less than 30 years; the lowest age of those affected being 35 years. In a study in Sweden, the age-specific incidence of cervical carcinoma in a population that did not undergo screening showed a peak at ages 45 to 50 years and a modest decline at older age [25] just like in our study.

The HGSIL and Low grade squamous intraepithelial lesion (LSIL) smears also followed the same pattern as the invasive smears with the age peak incidence being 40 to $49 \mathrm{yrs}$ but while there were 7 people with LSIL below age 30, only 4 people with HSIL were below that age. There was no HSIL found below 20 years. In a study done in Saudi Arabia the age peak incidence for invasive cancer and HSIL was 50 - 59 a decade later than what was found in our study [21].

The percentage of abnormal lesions over the total number of patients in the different age brackets shows that abnormality increases with age with a very steep increase after age 40 . This emphasizes the fact that there are more women affected with increasing age and hence the importance of screening.

\section{Conclusion:}

Cervical screening has been shown to be an effective tool in the detection of pre-invasive stages of cervical cancer and even limited Pap smear screening reduces the incidence. This emphasizes the need for wellorganized cervical screening programs and education of the public about cervical cancer and its precursors.

It is certainly going to be a mammoth task to create a mechanism to offer women cervical smears, with followup and referrals to specialist clinics for treatment if abnormal smears are detected, but if such steps are not taken, our women will continue to develop and die from what is essentially a preventable disease.

\section{References:}

[1]. Adebamowo C.A, Ajayi O.O, Breast cancer in Nigeria. West Afr J Med 2000;19:179- 194

[2]. Madong BM, Madaka AKJ, Mannaseh AN. Malignant disease in Jos: a follow up. Ann Afr Med 2003;2:48-53

[3]. Adefuye PO. Knowledge and practice of cervical screening among professional health workers in a suburban district in Nigeria. Nigerian Medical Practitioner 2006;50:19-22

[4]. Bassey EA, Ekpo MD, Abasiasia A. 2007. Female genital tract malignancies in Uyo, South- South, Nigeria. Nigerian Postgraduate Medical Journal 14:134-136.

[5]. Adewuyi SA, Shittu SO, Rafindadi AH. 2008. Sociodemographic and clinicopathologic characterization of cervical cancers in northern Nigeria. European Journal of Gynaecological Oncology 29:61-64.

[6]. Shafi MI. 2007. Premalignant and Malignant disease of the cervix. In: Edmonds DK, editor. Dewhurst's textbook of obstetrics and gynaecology. 7th ed. Oxford: Blackwell Publishing. P 614-624.

[7]. Jimoh AS, Abdul IF. A review of one hundred and three (103) histologically confirmed cases of carcinoma of the cervix at the University of Ilorin Teaching Hospital, Nigeria. Nigerian Medical Practitioner 2004;45: 55-60

[8]. Durosinmi-Etti FA. Cancer patients in Nigeria: causes of delay in diagnosis and treatment. Nigerian Quarterly Journal of Hospital Medicine 1985;3:28-30

[9]. Audu B.M, Elnafaty A.U, Pindiga H.U; Sporadic screening in a gynaecological clinic; Nig Med Pract. Vol51, No 6, 2007. (114 118)

[10]. Ayre J.E (1954). A simple office test for uterine cancer diagnosis. Can Med Ass J; 53:17 - 22

[11]. Richart,R., "Cervical Cancer in Developing Countries" ,In International Women's Health Coalition, special Challenges in Third World Women's Health. New York, 1990: p18.

[12]. Barnum,H.; Greenberg,R., "Cancers" In Jamison,D.; Mosley,W.; Measham, A.; Bobadilla, J., Disease Control Priorities in Developing Countries, Oxford: Oxford University Press, 1993, p551.

[13]. IARC Working Group on Evaluation of Cervical cancer screening programmes (1986). Screening for squamous cervical cancer: duration of low risk after negative results of cervical cytologyand it's implication for screening policies. Br. Med. J. 293 : 659 - 664.

[14]. Van Wijngaaden W.J, Duncan I.D, Hussain K.A (1995). Screening for cervical neoplasm Dundee \& Angus; 10 years on. British journal of obst. \& gynae. 102, $137-142$

[15]. Van Ballegooijen M. 2000. Overview of important cervical cancer screening process values in European Union (EU) countries, and tentative predictions of the corresponding effectiveness and cost-effectiveness. European Journal of Cancer 36:2177-2188.

[16]. Onah HE, Ezeugwu FO, Eze JN. 2001. Cervical cancer screening: A survey of current practice amongst Nigerian gynaecologists. Tropical Journal of Obstetrics and Gynaecology 18:78-81.

[17]. Chukwuali LI, Onuigbo WBO, Mgbor NC. 2003. Cervical cancer screening in Enugu, Nigeria. Tropical Journal of Obstetrics and Gynaecology 20:109-112.

[18]. Fadwa J. Altaf, Pattern Of Cervical Smear Cytology In The Western Region Of Saudi Arabia. Annals of Saudi Medicine, Vol 21, Nos 1-2, 2001; pg $94-96$ 
[19]. Obaseki DE, Nwafor CC.Cervical Cancer Screening In Benin City, South-South Nigeria IOSR Journal of Dental and Medical Sciences (IOSR-JDMS); Volume 5, Issue 1 (Mar.- Apr. 2013), PP 16-19

[20]. Samar Ghazal, Musmar M, D; Pattern and factors affecting pap smear test in nalblus, A retrospective study. Middle east journal of family medicine. 2004; vol.4(4)

[21]. Mbazor J.O, Umeora O.U, Egwuatu V.E; Cervical cytology profile of infertility patients in abakaliki, south eastern Nigeria. Journal of obstetrics and gynaecology February 2011;31 (2): 173 - 177.

[22]. Mansoor I; Profile of cervical smear cytology in western region of Saudi Arabia. The internet journal of pathology 2002.Vol.2 number 1 .

[23]. Elhakeem HA, Al-Ghamdi AS, Al-Maghrabi JA. Cytopathological pattern of cervical Pap smear according to the Bethesda system in Southwestern Saudi Arabia. Saudi Med J. 2005 Apr; 26(4):588-92.

[24]. Obafunwa JO, Sagay AS, Otubu JAM; Prevalence of Cervical Intraepithelial Neoplasia. Tropical Journal of Obst. \& Gynaecology. 1991.vol 9: $16-17$.

[25]. Spare'n P. Early detection and screening for cancer of the cervix in Sweden during the 20th century. Akademisk avhandling. Almqvist \&Wiksell International. Uppsala universitet. 1996. ISBN 91-554-3725-7. 